\title{
Simulation Study on Interception Probability of Anti-Torpedo Torpedo
}

\author{
Shifu ZHANG ${ }^{\mathrm{a}}$, Qian $\mathrm{ZHAO}^{\mathrm{b}}$, Yu GUO ${ }^{\mathrm{a}}$ and Weichen $\mathrm{LI}^{\mathrm{a}, 1}$ \\ ${ }^{a}$ System Engineering Research Institute, China Shipbuilding Group Co., Ltd, Beijing \\ ${ }^{\mathrm{b}}$ Beijing Sunwise Space Technology Ltd.
}

\begin{abstract}
In this paper, a simulation study on the hit probability of an anti-torpedo torpedo(ATT) intercepting an incoming torpedo is con-ducted. A mathematical model of anti-torpedo torpedo interception trajectory is established. Through Monte Carlo simulation cal-culation, the influence of four errors on interception probability of anti-torpedo torpedo intercepting non-guided torpedo is quan-titatively analyzed. In addition, according to the principle of anti-torpedo torpedo interception fixed advance angle guided torpedo, by analyzing the movement trajectory of the incoming torpedo, ATT, and ship, the influence of the ship on the interception proba-bility under the three offset situations is simulated and calculated.
\end{abstract}

Keywords. Anti-torpedo Torpedo, interception trajectory, interception probability, Monte Carlo method.

\section{Introduction}

With the continuous development of torpedo technology, an important threat to surface ships and submarines is from the modern high-performance intelligent torpedoes [1]. In this case, the decoy effect of soft countermeasures such as noise jammers and acoustic decoys on torpedoes is gradually reduced. The hard kill and defense system with antitorpedo torpedo (ATT) as counter weapon is becoming a con-centrated research area in many countries [2]. We should closely follow the latest developments of ATT, digest and absorb latest research and development technology and experience, and prepare for ATT de-sign and research work [3].

In this paper, a computer simulation analysis of the hit probability of an anti-torpedo torpedo inter-cepting an incoming torpedo is carried out. A mathe-matical model of antitorpedo torpedo interception trajectory is established. The influence of four kinds of errors (ATT velocity error, ATT azimuth error, in-coming torpedo velocity error, incoming torpedo azi-muth error) on the probability of interception when anti-torpedo torpedo intercepted non-guided torpedo is quantitatively analyzed through Monte Carlo sim-ulation calculation. In addition, the ATT intercept probability when the guidance method is added to the incoming torpedo is simulated and analyzed.

${ }^{1}$ Corresponding Author, Weichen LI, System Engineering Research Institute, China Shipbuilding Group Co., Ltd, Beijing, China; Email: 214200838@qq.com. 


\section{Mathematical Model of Att Interception Ballistics}

The ATT interception trajectory is related to many factors, including hydrological conditions, the attack trajectory form and movement parameters of the attacking target, and the attack trajectory form and movement parameters of the attacking torpedo. This chapter mainly studies the attacking torpedo with a fixed advance angle after the ATT is launched. The following mathematical model of interception trajectory is given, as shown in figure 1.

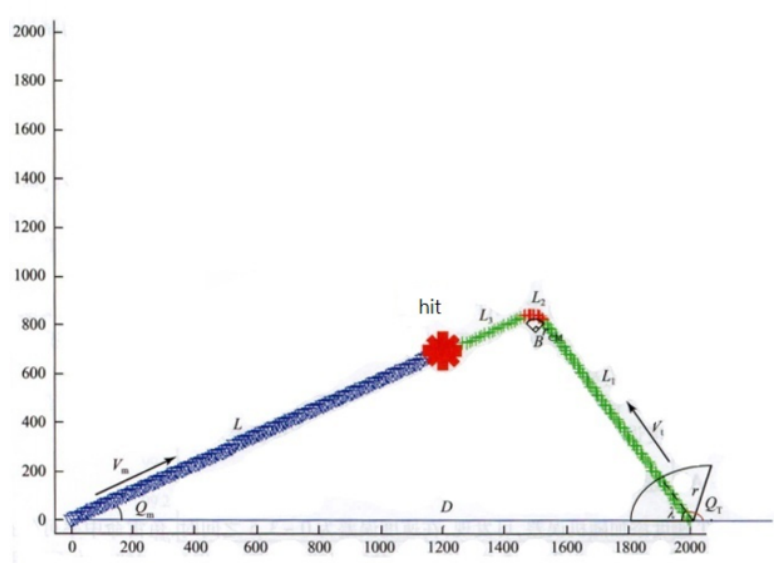

Figure 1. Mathematical model of ATT interception trajectory.

Trajectory of incoming torpedo: the blue part in the picture. We have established a two-dimensional coordinate system for the origin of the attacking tor-pedo, and the attacking torpedo will go straight for L distance at a constant speed under the condition that the moving speed Vm and the moving azimuth Qm are known.

ATT trajectory: the green part and the red sec-tion between the green part in the picture. Taking into account the influence of various factors, the straight sailing + headon interception trajectory is designed, which is mainly divided into three parts, namely, the straight sailing section, the gyroscopic section, and the straight sailing section of the head-on interception at the initial stage of the search. It can be known that the ballistic interception scheme of head-on reverse interception has a higher intercept probability than the direct-line intercept scheme [5], so we choose the head-on reverse interception ballistic interception scheme. This scheme can intercept the incoming tar-get in time and minimize the influence of the distance and heading errors of the incoming torpedo.

Straight sailing L1: After the ATT is launched, the movement distance of the fixed speed and straight sailing under the condition that the movement speed and the movement azimuth are known.

Cycle L2: ATT makes a $90^{\circ}$ gyration at a constant rotational angular velocity with point $\mathrm{B}$ as the center. The gyration radius is $\mathrm{rCM}$, and the arc length of this segment of motion is recorded as cycle L2.

Straight sailing L3: After the maneuver is over, continue to do a fixed-speed straight sailing at the same speed as L1 until it encounters the incoming torpedo and hits the target. The movement distance of this segment is recorded as straight sailing L3. 


\section{Att Capture Target Conditions}

ATT is launched at a fixed advance angle, and gradually approaches the incoming torpedo according to a specific trajectory. In order for the ATT to capture target, the incoming torpedo must be required to enter the effective range of the guidance device, that is, fall into the guidance sector, and the following constraints must be met:

- The distance between the ATT and the incoming torpedo is less than the guidance distance of the ATT.

- The angle between the heading of the ATT and the line between the ATT and the incoming torpedo is less than the half-angle of the guidance sector.

When the above two conditions are met, it is considered that the ATT captures the incoming tor-pedo. Without considering the guidance of the ATT capture sector, assuming that the incoming torpedo enters the radius of the ATT guidance sector, it is con-sidered that the target is successfully intercepted.

\section{Simulation Results and Analysis of Hit Probability of ATT Intercepting Unguided Torpedo}

Setting parameters: incoming torpedo speed $25 \mathrm{~m} / \mathrm{s}$, heading $30^{\circ}$ (angle with horizontal axis). The ATT speed is $25 \mathrm{~m} / \mathrm{s}$, heading $120^{\circ}$ (the angle between the horizontal axis ,relative with the course of the incoming torpedo), the power range is $10 \mathrm{~km}$, the turning angular velocity is $15 \%$, the active acoustic self-guidance action distance is $100 \mathrm{~m}$, and the self-guidance function The sector is $100^{\circ}$, and the ATT fuse has a range of $100 \mathrm{~m}$. The initial distance between ATT and incoming torpedo is $2 \mathrm{~km}$ (in the above parameters, the course of incoming torpedo and ATT are variable parameters, and the other pa-rameters are regarded as fixed parameters. If the course parameter is changed, under certain parame-ters, it will be affected by the speed of incoming tor-pedo and ATT, there will be a situation where ATT cannot hit the incoming torpedo).

Adopt Monte Carlo method for simulation calculation, and the simulation times are 10,000 times. In reality, the speed and azimuth of the ATT and the incoming torpedo are not fixed, and there will always be some random errors. The following is a simulation calculation analysis of the impact of the torpedo velocity error and azimuth error, as well as target velocity error and azimuth error on the hit probability.

\subsection{The Influence of Att Speed Error on Hit Probability}

Adding random errors to the ATT speed, it can be found that when the speed error is between 0 and $3.5 \mathrm{~m} / \mathrm{s}$, the ATT hit rate can be maintained above $90 \%$; when the speed error is between 2.5 and $6 \mathrm{~m} / \mathrm{s}$, the ATT hit rate is lower The decay speed (slope) is generally regarded as constant, stable at about $8 \%(\mathrm{~m} / \mathrm{s})$, so the ATT speed error has a greater impact on the hit rate of the incoming torpedo, as shown in figure 2.

\subsection{The Influence of Att Speed Error on Hit Probability Heading}

Adding a random error to the ATT azimuth, it can be found that even if the ATT azimuth error changes by $8^{\circ}$, the hit rate still has no effect. We speculate that because the model 
selection only con-siders target capture, that is, as long as the target falls into the search sector, it is regarded as a hit, and does not consider the guidance movement of the target at close range. Therefore, the existence of the sector search area greatly compensates for the ATT azimuth error, so the ATT azimuth error has little effect on the hit probability of an incoming torpedo, as shown in figure 3 . (The hit probability $100 \%$ in this figure has a certain relationship with the selection of the ATT search sector).

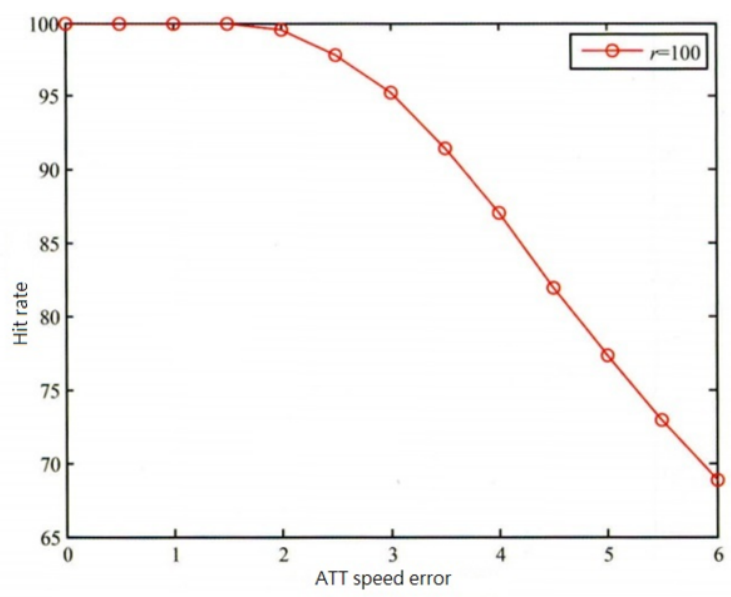

Figure 2. The variation of ATT hit rate with ATT speed error.

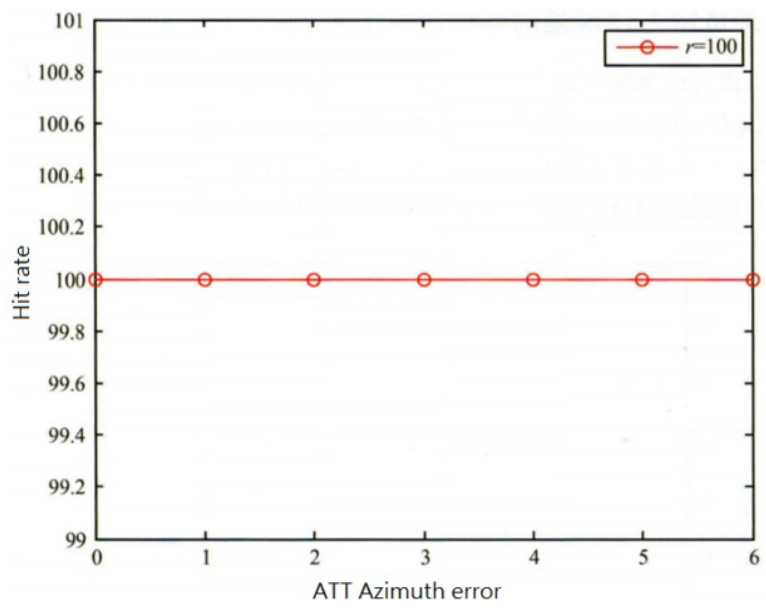

Figure 3. The variation of ATT hit rate with ATT azimuth error.

\subsection{The Impact of Incoming Torpedo Speed Error on Hit Probability}

Adding random error to the incoming torpedo speed, it can be found that when the speed error is less than $12 \mathrm{~m} / \mathrm{s}$, the hit rate is over $90 \%$, and when the speed error continues to increase, the hit rate drops rapidly. Since the attacking torpedo has been moving in a straight line, and its running speed is not much greater than that of ATT, as long as the azimuth does not deviate, it is likely to fall into the ATT capture sector and be regarded 
as a hit. Therefore, the impact of the target speed error within a certain range on the hit rate is also small, and the impact beyond this range is large. As shown in figure 4.

\subsection{Impact of Azimuth Error of Incoming Torpedo on Hit Probability}

Adding random error to the azimuth of the incoming torpedo, it can be found that when the azimuth error is between $1^{\circ}$ and $2.25^{\circ}$, the ATT hit rate can be maintained above $90 \%$; when the azimuth error is between $1.5^{\circ}$ and $5^{\circ}$, the ATT hit rate can be found The attenuation speed (slope) of the torpedo hit rate is roughly stable at about $11.5 \% /\left(^{\circ}\right)$. If the moving direction of the attacking torpedo is shifted, it is not easy to enter the capture sector smoothly. Therefore, the azimuth error of the attacking torpedo has a greater impact on the hit rate of the ATT. Large, as shown in figure 5.

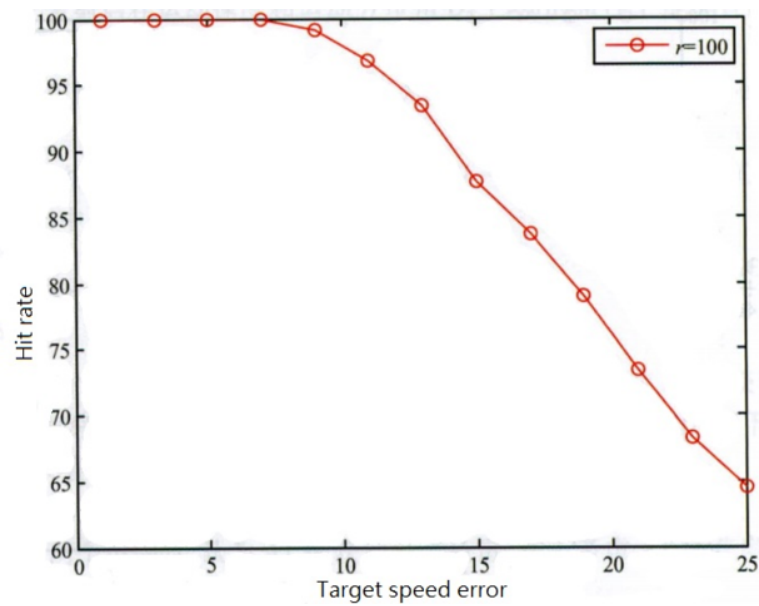

Figure 4. The variation of ATT hit rate with incoming torpedo speed error.

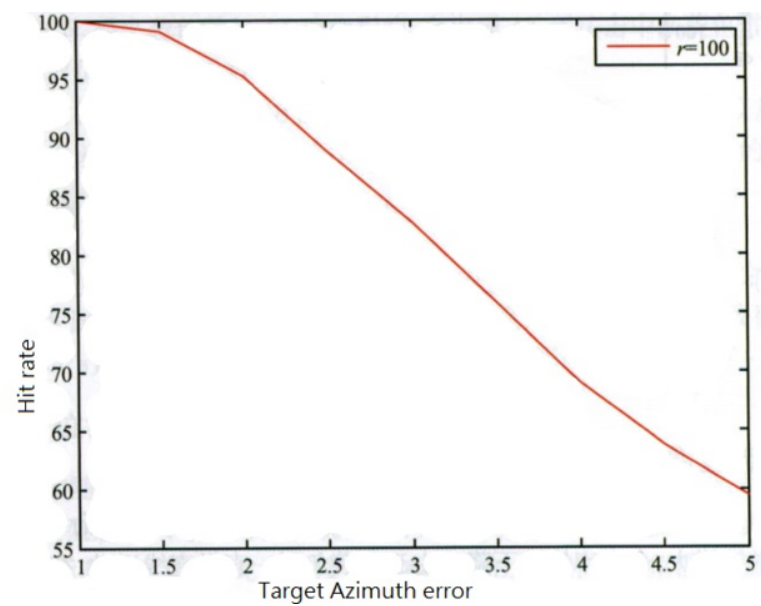

Figure 5. The variation of ATT hit rate with incoming torpedo azimuth error. 


\subsection{Result Analysis}

In the initial model built in this section without guidance, the ATT velocity error and the incoming torpedo azimuth error have a greater impact on the hit rate, which are $8 \% /(\mathrm{m} / \mathrm{s})$ and $11.5 \% /\left({ }^{\circ}\right)$, respectively. As the model is simplified, the ATT azimuth error and the incoming torpedo velocity error have little effect on the hit rate.

\section{Principles and Simulation of Att Intercepting Guided Torpedoes}

Based on the establishment of the ballistic model and the capture model, a fixed advance angle guidance method is added to the movement of the incoming torpedo relative to the ship.

\subsection{Principles of Att Intercepting Fixed-Advance Angle Guided Torpedoes}

The fixed lead angle guidance method is that the lead angle of the incoming torpedo is always fixed to a non-zero constant. During the guidance process, the speed direction of the incoming torpedo points to the front of the movement with a fixed advance angle. The model is shown in figure 6 .

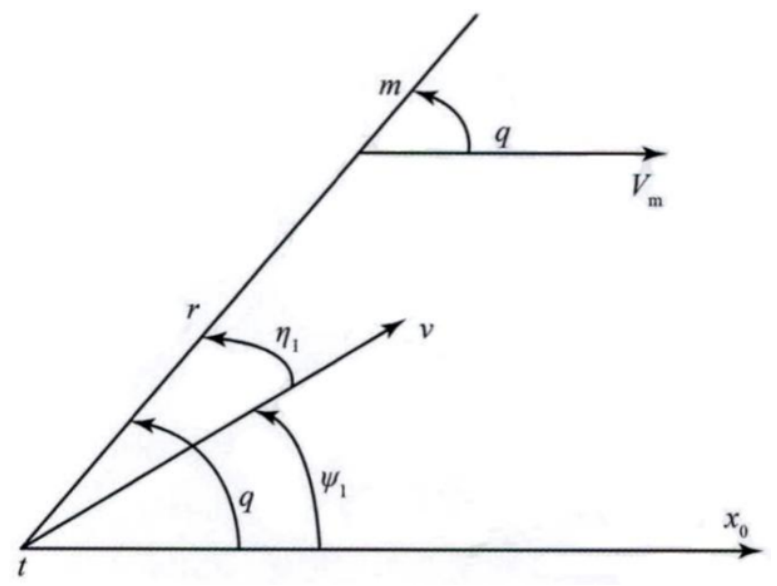

Figure 6. fixed advance angle guided module.

In the figure, $\mathrm{m}, \mathrm{vm}$ are the position and movement speed of the ATT (ship). t, v are the position and movement speed of the incoming torpedo; $\eta_{-} t$ is the fixed advance angle of the incoming torpedo; $r$ is the distance between the ATT and the incoming torpedo in motion. There are the following relative motion equations:

$$
\begin{aligned}
& \frac{\mathrm{dr}}{\mathrm{dt}}=\mathrm{v}_{\mathrm{m}} \cos \mathrm{q}-\mathrm{v}_{\mathrm{t}} \cos \eta_{\mathrm{t}} \\
& \frac{\mathrm{dq}}{\mathrm{dt}}=\frac{1}{\mathrm{r}}\left(\mathrm{v}_{\mathrm{t}} \sin \eta_{\mathrm{t}}-\mathrm{v}_{\mathrm{m}} \sin \mathrm{q}\right)
\end{aligned}
$$




$$
\mathrm{q}=\psi_{\mathrm{t}}+\eta_{\mathrm{t}}
$$

It is necessary to know the movement speed $\mathrm{v}$ of the incoming torpedo, the fixed advance angle $\eta_{\mathrm{t}} \mathrm{t}$ of the incoming torpedo, the initial distance $r$ between the incoming torpedo and the ship, and the movement elements of the ship (including the movement direction and speed of the ship V_m, the ship The angle between the direction of movement of the ship and the line of sight $q$ ). That is, by solving $r, q, \psi_{-} t$, the movement of the ship is used to guide the movement of the incoming torpedo.

\subsection{Simulation Results and Analysis}

Take the ship's moving direction as the positive direction of the horizontal axis and the position when the ATT is released as the origin to establish a coordinate system. The initial distance between the incoming torpedo and the ship is $2 \mathrm{~km}$, the incoming torpedo does not capture the sector, and the fuse distance is $15 \mathrm{~m}$. The incoming torpedo moves with a fixed advance angle $\left[\mathrm{Q}_{-} \mathrm{m} / \eta \rrbracket \mathrm{t}=\pi / 6\right.$ and an initial angle $\eta / \mathrm{q}=\pi / 3$. The speed of the incoming torpedo and ATT are both $25 \mathrm{~m} / \mathrm{s}$. The movement speed and movement direction can be changed by itself, and the movement trajectory of the attacking torpedo can be solved by the known movement elements of the ship and the movement speed of the incoming torpedo, and the launch of a fixed advance angle. As shown in figure 7.

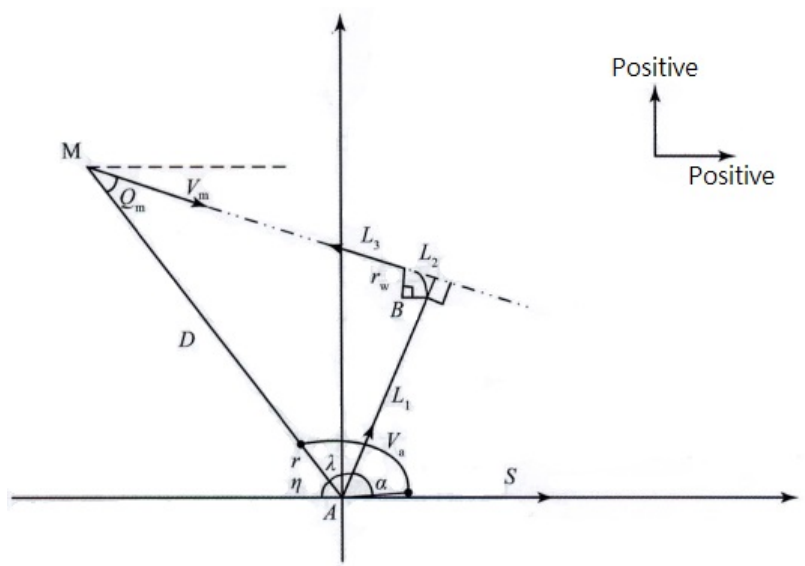

Figure 7. Solve the trajectory of the incoming torpedo.

On the basis of the above parameter settings, set the ship's speed to $15 \mathrm{~m} / \mathrm{s}$ and $0^{\circ}$ deflection, then the motion trajectories of the incoming torpedo, ATT, and ship are shown in figure 8 . 


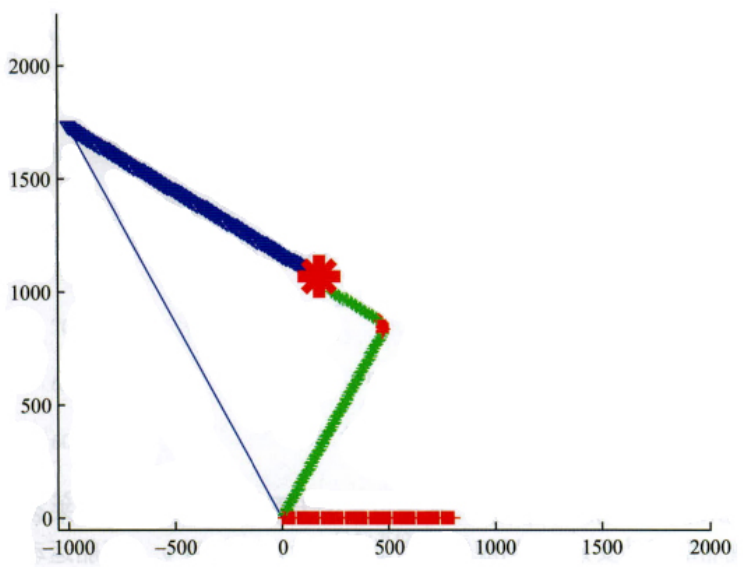

Figure 8. Incoming torpedo, ATT and ship motion track.

Since it is assumed that the incoming torpedo and the ship are moving in a uniform straight line and finally meet at a point (hit the ship), the relative displacement line between the incoming torpedo and the ship is always parallel to the initial relative displacement (the angle $\eta / q$ does not change during the movement, D decreases). In order to more conveniently and intuitively see the role of the fixed advance angle guidance of the incoming torpedo, we assume that the moving speed of the ship is $15 \mathrm{~m} / \mathrm{s}$, the ship's offset directions are $0^{\circ}$, upward offset $5^{\circ}$, and downward offset $5^{\circ}$, and the fuse distance of the incoming torpedo is $15 \mathrm{~m}$. The movement trajectory of the incoming torpedo and the ship is shown in figure 9, figure 10 and figure 11.

(1) Ship offset $0^{\circ}$.

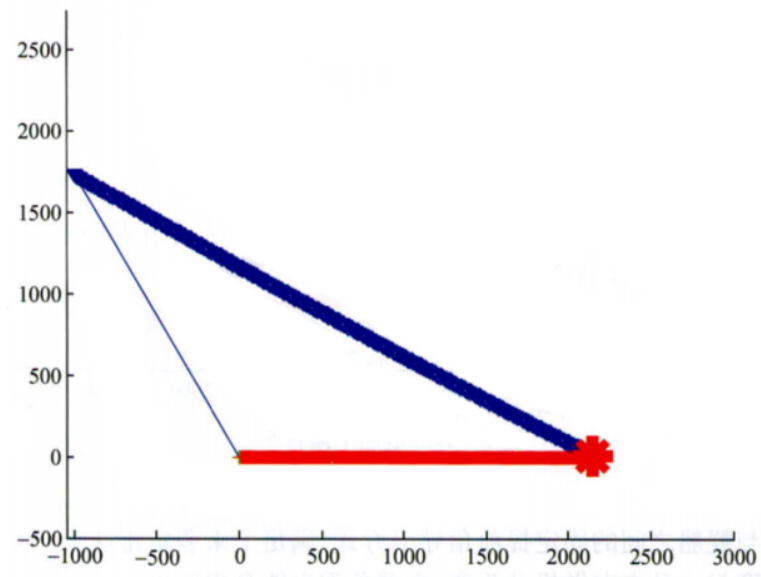

Figure 9. Ship offset $0^{\circ}$.

(2) Ship up offset $5^{\circ}$. 


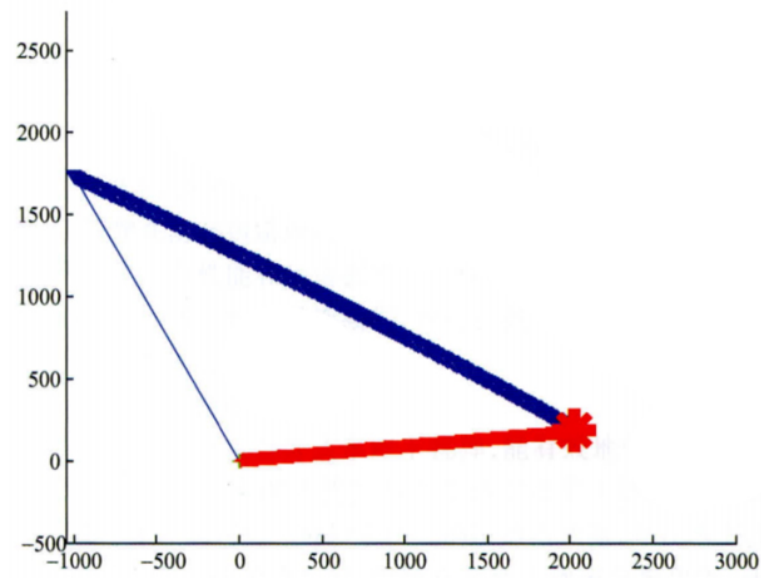

Figure 10. Ship up offset $5^{\circ}$.

(3) Ship down offset $5^{\circ}$.

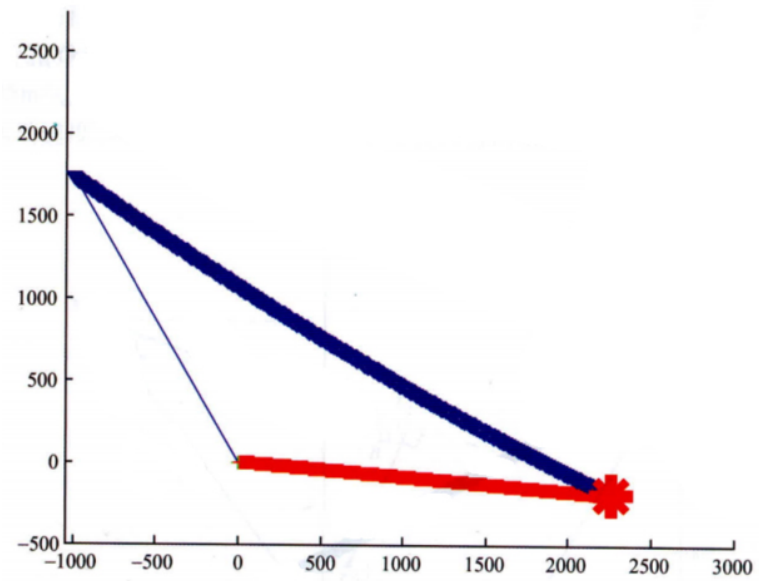

Figure 11. Ship down offset $5^{\circ}$.

The fixed advance angle guidance method be-tween the incoming torpedo and the ship satisfies the premise of a certain speed of the incoming torpedo, even if the speed and direction of the movement of the ship are changed maneuvering, the incoming torpedo can hit the ship.

\section{Conclusion}

This paper analyzes the influence of four kinds of errors on the probability of interception when the anti-torpedo torpedo intercepts the non-guided torpedo, and the influence of the ship on the probability of interception under the three kinds of deviations. The simulation results in this paper are all based on certain capture target conditions, and further in-depth research can be carried out according to specific requirements. The 
computer simulation analysis results of anti-torpedo torpedo interception probability in this paper have played a certain reference and guidance role, and can provide reference for anti-torpedo torpedo design work.

\section{References}

[1] Cui Guiping. Current status and development trend of foreign anti-torpedo torpedo technology. Torpedo Technology, 2012, 20(6).

[2] You Dade, Xu Demin. Simulation analysis of factors affecting the interception probability of anti-torpedo torpedoes. Torpedo Technology, 2010, 18(4).

[3] Ding Zhendong. Research on key technologies of anti-torpedo torpedoes. Torpedo technology, 2007, 15(1).

[4] Meng Qingyu, Zhang Jingyuan, Song Baowei. Analysis of Torpedo Combat Effectiveness [M]. Beijing: National Defense Industry Press, 2003.

[5] Li Xiaoning, star, Zhu Ruohan. Anti-torpedo torpedo interception trajectory and probability of interception. Torpedo technology, 2008, 16(3). 